\title{
ELDERLY HUSBANDS CARING AT HOME FOR WIVES DIAGNOSED WITH ALZHEIMER'S DISEASE: ARE MALE CAREGIVERS REALLY DIFFERENT?
}

\section{Suzanne Cahill}

In Australia, there is a dearth of literature available on men as principal carers despite reports which show that in the $60+$ age group, looking after a sick spouse becomes the major form of caregiving and men as carers predominate (ABS, 1993). The paper reports findings from a study of 26 aged husbands who cared at home for their cognitively impaired wives. Indepth interviews collected quantitative and qualitative data about men's caregiving experiences. Findings challenge the literature about the role gender plays in evoking care and service responses. Results show how men demonstrated a strong injunction to care, performed intimate personal care tasks competently, received limited government support and derived some satisfaction from the caregiving role. Despite similarities between male and female caregivers being noted, some gender differences in the way in which men approached the care role are described. The need for community care policies to be more sensitive to the gendered context of elderly care provision is discussed.

\section{Introduction}

There has been a myriad of published research on female caregiving (Ungerson, 1987; Lewis \& Meredith, 1988; Brody, 1990; Aronson, 1991; Opie, 1992; Finch \& Mason, 1993; Leira, 1994; Cahill, 1997). Although work on men in principal care roles is beginning to emerge, it is argued that male carers are still a neglected population sub-group (Siriopoulos, Brown \& Wright, 1999). In Australia, only one study of Sydney-based male caregivers appears in the literature (Brown, 1996) despite evidence showing that there are many male caregivers in the over 60 year age group (ABS, 1993). Given increased longevity and statistics showing an increase in sex ratio with a

Dr Suzanne Cahill, Director of the Dementia Development Centre, St James Hospital, Dublin, Ireland. e-mail: director@stjames.ie. 
slight decrease in life expectancy between males and females (Borowski \& Hugo, 1997), the issue of older persons caring for older spouses, including husbands caring for cognitively impaired wives will become increasingly important. To plan effective services there is a need to understand more about the world of male caregivers and to learn more from men themselves about the social, economic and emotional resources required by them when performing the principal care role. The social issue of ageing and the management of women with dementia by their older frail husbands will require critical attention.

The research described here is a first attempt, in Queensland, to broaden the debate on male caregivers of spouses with dementia and to explore the complexities of their worlds. The aim of the study is to develop an understanding of the caregiving experiences of men looking after spouses diagnosed with dementia and in so doing highlight (i) their motivation to care, (ii) the caring tasks undertaken, (iii) the formal and informal support services received, and (iv) their attitudes to caring including satisfaction with the principal care role. Where feasible results will be compared with a recent study of female caregivers already reported in the literature (Cahill \& Shapiro, 1998).

\section{Literature Review}

In Australia, there exists no systematic body of literature on the topic of male caregivers (Brown, 1996), a finding probably best explained by the fact that the main bulk of principal caregivers in Australia are women (Schofield, Herrman, Bloch, Howe \& Singh, 1997) and caregiving research has traditionally been a women's issue (Rosenman, Tilse, Le Brocque \& Grasso, 1993) undertaken predominantly by women about women (Paul, 1999; Cahill, 1999; Cahill, 1997). In the United States, an emerging body of literature has led to a description of men in caring roles as 'misunderstood caregivers' (Harris, 1993). Harris argues for the need for more exploratory research on male caregivers. Drawing on the literature, he demonstrates emerging contradictory findings about male caregivers, with some studies arguing that men feel closer to their wives after caring and experience improved relationships, while others show how for men, caregiving deminishes the companionship/confidant dimension of the relationship and increases tension. Harris points to methodological problems arising from inappropriate research designs being used in male caregiver reseearch and suggests that these contradictions illustrate the need for more in depth 
exploratory research to gain a better understanding of men's caregiver worlds (Harris, 1993).

In the United Kingdom, male carers have also been discovered (Fisher, 1994). A primary focus has been on comparing the respective experiences of men and women and noting the differences (Miller, 1987; Ungerson, 1987). Although some controversy exists regarding the nature and extent of these differences, a consistent finding is that men's approach to caregiving differs from that used by women (Kaye \& Applegate, 1990).

Men tend to use a problem-solving approach to caregiving - an approach which may be carried over from their work roles (Harris, 1993) and which may enable them to set limits to caring activities, thereby protecting themselves from the burden, depression and guilt often experienced by women (Kaye \& Applegate, 1990). Others argue that older wives see caring as a continuation of their nurturant role, while husbands see the role as more task-oriented because of previous work in the external world (Finch \& Groves, 1983). Miller's study of husband and wives caring for their infirm spouses found that women tended to focus on changes in relationships brought about by the care-recipient's infirmities, whereas men tended to focus on specific tasks (Miller, 1990).

Several studies show that male caregivers particularly husbands are more likely than females to receive support services from both formal and informal sources (Johnson, 1983; Stoller \& Cutler, 1992; Zarit, Todd \& Zarit, 1986). Synder and Keefe found that male caregivers were more inclined to seek assistance with housework whereas women used support groups (Snyder \& Keefe, 1985). Twigg and Atkin argued that men were more able to distance themselves in the care role and felt comfortable about asking for assistance (Twigg \& Atkin, 1994). Kaye and Applegate showed that male caregivers experienced emotional gratification by providing care, (Kaye \& Applegate, 1990).

It has been noted that men's motivation to care may be different from women's. Men are said to be drawn into caregiving roles out of a sense or love (Mathew, Mattocks \& Slatt, 1990) while women care because of duty (Ungerson, 1987) or because of gendered kinship obligations (Finch \& Mason, 1993). Siriopoulus and his colleagues have recently shown in a study of male caregivers, that the decision to care came easily to these men, who although faced with difficult care tasks, reported a commitment to look after their wives as long as they were physically possible (Siriopoulus, Brown \& Wright, 1999). The quality of the previous relationship was the bond that held together caregivers with care-receivers. Interestingly, Bytheway's work in the United Kingdom challenged some theoretical formulations about the 
role gender played in evoking the caring response (Bytheway, 1987). Bytheway also demonstrated that for older husbands, caregiving could be motivated by a deep sense of reciprocal obligation and a concern to respond to the needs of the care-recipient.

Other writers note that men are more likely to be acknowledged for their caring (Guberman, 1988), and to receive praise since male caring is often viewed by society as an unexpected expression of compassion (Hooyman, 1989). Husband carers may feel closer to their wives after they commence caring than before (Fitting, Rabins, Lucas \& Eastham 1986; Motenko, 1988). Drawing on the works of others, Ungerson, demonstrated that men who take on 'tending' often remain exempt from dealing with human excreta and from managing intimate personal care (Ungerson, 1983).

\section{Methods}

Between June 1998 and March 1999, all referrals to the Aged Care Assessment Team (ACAT) at the Prince Charles Hospital in Brisbane which satisfied the study's eligibility criteria were included in the research. Principal carers were eligible to participate if they were (i) male, (ii) caring for a wife diagnosed with Alzheimer's Disease or a related dementia, and (iii) married to that wife for at least 5 years. Prior to assessment, carers were contacted by ACAT team members, when a date and time for assessment was arranged. During initial contact, information about the study was provided and consent was sought from husband carers to participate in the research. Twenty six out of twenty eight husbands (93\%) informed about the study agreed to participate. All but two interviews were taped and later transcribed. Interviews lasted approximately one and a half hours and took place in the caregiver's home.

Several limitations to the design of this work must be acknowledged. First, like most caregiver research, a non-probability sample, biased towards services users was used. Findings therefore need to be interpreted carefully and cannot be generalized. Secondly, while both quantitative and qualitative methods are employed, a preferred approach might have been to use qualitative methods more extensively. This would have enabled a more indepth exploration of the complexities of men's personal experiences. The approach would also mean however, that valuable insights into service needs and uses would have been lost. Third, it needs to be noted that respondents had been provided home care for an average period of four years, a point which needs to be remembered in interpreting the data, since for some participants recall bias may have posed a problem. 


\section{Measures}

A semi-structured questionnaire designed to collect quantitative and qualitative data was developed and piloted. This data collection instrument had two distinct components. In the first section, information was sought about the cognitively impaired persons' health status including dementia classification, time since diagnosis and the presence of additional health problems which might complicate caregiving. To document care-receivers' cognitive status, the Mental Status Questionnaire (MSQ) was administered and a mean score was computed. A score of 1 was attained for each question answered correctly. ${ }^{1}$ To record the care-receivers' physical dependence, the Modified Barthel Index (MBI) was administered. ${ }^{2}$ A mean score was computed. In the second part of the interview schedule, the focus turned to caregiver issues. Information was asked about reasons for caregiving, care tasks done, time spent caring, formal and informal support received and satisfaction with the role.

\section{Data Analysis}

Quantitative data was analysed using SPSS. In view of the small sample size, frequencies and measures of central tendency are only reported. A model for analysing qualitative data which includes (i) data reduction, (ii) data display, and (iii) conclusion, drawing/verification was carefully followed (Miles \& Huberman, 1994). The main strategy used for data reduction was grouping together responses according to particular themes and conducting within-case and cross-case analyses. The within-case analysis sought to link data with explanations and tried to understand why phenomena occurred as they did. The cross-case analysis was then conducted between multiple cases, grouping together answers from different people to common questions. Secondly, data were displayed. When responses to open-questions were written out, a code book was developed and data derived from questions along with unsolicited data collected by audio-tape were displayed. Thirdly, data verification was undertaken and conclusions were drawn. The meanings emerging from the data were tested for their plausibility and validity against data collected from fixed choice questions. The qualitative data which emerged from the interviews provided detail and context. A focus on respondents own words and their personal interpretations greatly enhanced an understanding of the complexities of the men's caregiving worlds.

\section{Results}

\section{Demographic Profile of Male Caregivers}

Table 1 shows the demographic characteristics of the sample. 
Table 1: The demographic characteristics of male caregivers

\begin{tabular}{|l|l|l|}
\hline Demographic Characteristics & $\mathbf{N}$ & $\%$ \\
\hline N=26 & & \\
Country of birth & & \\
Australia & 20 & $77 \%$ \\
Other & 6 & $23 \%$ \\
Mean time caring in years & 4 & \\
Range & $6-13$ & \\
Standard deviation & 3 & \\
Mean age of caregiver in years & 74 & \\
Range & $55-87$ & \\
Standard deviation & 9 & \\
Mean duration of marriage in years & 44 & \\
Range & $9-60$ & \\
Standard deviation & 13 & \\
Educational Status & & \\
Primary & 8 & $50 \%$ \\
Secondary & 13 & $19 \%$ \\
Tertiary (including technical) & 5 & \\
Employment Status & & $92 \%$ \\
Retired & 24 & $8 \%$ \\
Working & 2 & \\
Occupational Background & & $4 \%$ \\
Professional & 1 & $19 \%$ \\
Managerial & 5 & \\
Skilled & 8 & \\
Semi-skilled & 8 & \\
Unskilled & 4 & \\
\hline
\end{tabular}

All the male caregivers were born in Australia or in other English speaking countries. Three were born in the United Kingdom, two came from America and one had recently relocated to Australia from New Zealand. Carers had a mean age of 74 and most were partners in long- term marriages. Half reported they had received a secondary school level of education and all but two had retired from work. In seven of these cases (30\%) respondents reported they retired from work to care. Male caregivers came from a diverse range of occupational backgrounds and included, a university lecturer, an army lieutenant, an air-traffic control officer, a fire officer, a painter, a farmer, a fitter, a carpenter, taxi driver, a truck driver, a hairdresser. Each had a history of sharing a home, a daily life and an identity as part of a couple. All but one had children and many were both grand-parents and great-grandparents. In a small number of cases $(n=4)$ carers were partners in second 
marriages. In one of these cases, the male caregiver was 20 years younger than his wife. In another unusual case, a spouse who had been placed in a nursing home had recently been taken home by her husband. All but five of the respondents now lived in couple-only relationships their children having grown up and left home.

\section{The Health Profile of Care-Receivers}

To explore the health status of care-receivers, respondents were asked to report (i) what the general practitioner told them at diagnosis about dementia and whether adequate information was provided, (ii) when was the dementia diagnosed and when did the carer first notice the memory problems, and (iii) what additional health problems were experienced by their wives. Table 2 presents these results along with data collected on cognitive deficits and functional profiles of care-receivers as measured by the Mental State Questionnaire (MSQ) and the Modified Barthel Index (MBI).

Table 2: The type of dementia, health status, cognitive impairment and dependency level of care-receivers

\begin{tabular}{|l|c|}
\hline Characteristics of care-receivers & $\mathbf{N}(\mathbf{n}=\mathbf{2 6})$ \\
\hline Dementia & 18 \\
Alzheimer's Disease & 3 \\
Vascular Dementia & 1 \\
Parkinson's Disease & 1 \\
Cortical Degeneration & 1 \\
Binswenger Disease & 1 \\
Encephalitis & 1 \\
Pick's Disease & 3 \\
Mean time since diagnosis (in years) & $0.25-12$ \\
Range & 3 \\
Standard deviation & 5 \\
Mean time since memory problems first identified (in years) & $0.1-12$ \\
Range & 3 \\
Standard deviation & \\
Other Health Problems & 8 \\
Arthritis & 6 \\
Coronary Heart Disease & 5 \\
Hypertension & 5 \\
Depression or problems with nerves & 4 \\
Other & 3.1 \\
Mean score on Mental State Questionnaire & 84 \\
Mean score on Modified Barthel Index & \\
\hline
\end{tabular}


The majority of care-receivers $(n=18)$ were diagnosed with dementia of the Alzheimer's Disease and smaller numbers $(n=8)$ were diagnosed with the other listed dementias. When asked, more than two thirds (69\%) reported they were given sufficient information about dementia at diagnosis. A small minority $(n=8)$ stated they would have liked more information, including details about the cause and progression of dementia, practical suggestions on problem behavioural management and more service information. Mean time since diagnosis was 3.25 years. Mean time since memory problems were first identified by principal caregivers was 5 years ( which meant that in some cases, there was a delay period of up to 2 years before a medical diagnosis of dementia was made).

The table lists other health conditions (apart from dementia) experienced by care-receivers and reported by principal caregivers. A total of 20 out of 26 caregivers $(77 \%)$ reported their spouses had other illnesses. Approximately one third suffered from arthritis. Another one quarter were diagnosed with either coronary heart disease, hypertension or depression. A small number of care-receivers had other illnesses, such as cancers, ulcers, diabetes, circulatory and respiratory problems. Several of the women had multiple pathologies, a finding not surprising given the age distribution of carereceivers. The table also shows that the mean MSQ score was 3.1. Nine care-receivers $(34 \%)$ scored 0 which meant their cognitive functioning was severely impaired. The mean Barthel score was 84 . One care-receiver was severely physically dependent (MBI was 25), 11 were moderately dependent $(\mathrm{MBI}=61$ to 90$)$ and 7 were slightly dependent $(\mathrm{MBI}=91$ to 99$)$.

For many of the men, the practicalities of looking after a loved one with a dementia were complicated due to the interplay between memory loss problems, problem behaviours and other listed health conditions. One husband told his story about how his wife who had diabetes constantly resisted his efforts to ensure she follow a special diet:

The diabetes and arthritis make the caring load even more difficult and of course she's stubborn. She wants everything with sugar. When we go shopping she picks everything up with sugar. I like that, you can't have that. But there's no point in buying something I know she can't have, so I buy everything substituted.

For many of these elderly men, caregiving had become the dominant focus of their worlds. An 83 year old, married some 60 years, talked about what caregiving meant to him: 
All the time I' $\mathrm{m}$ thinking is she alright, is she smoking, or is she doing this, or do you know has she fallen over or has she had a blackout?

\section{Reasons for caring}

To explore why care roles and responsibilities were first adopted, respondents were asked 'why do you provide home care?' Main reasons for caring included love, marriage, duty or a combination of each (see table 3 ). The all-encompassing commitment of these older men to provide care to a cognitively impaired wife was a dominant feature of most of the interviews, as was reciprocity and the notion that 'she would have done the same for me'. Interviews also revealed the strength of beliefs in the marriage vows, the power of marriage in determining care roles and the idea that a core responsibility within marriage was to care 'in sickness and in health'. These points were clearly illustrated in several of the interview responses to the question 'why do you care?':

She's my wife and partner, we've done everything together for 41 years, you take your vows. We've been a team. You just don't stop it now for better or for worse.

I made a promise when I married her for better or for worse.

You make vows when you get married. If you believe in vows then you intend to keep them.

Caregiving obligations were based not only on marital and religious vows, 'when I married her I made a vow before God and the congregation', but also on a sense of fairness and a desire to pay back a loved one for past favours bestowed. The majority had enjoyed happy and fulfilling marriages: 'I love her very dearly, we've had a fantastic marriage and life for us has been wonderful' and most had a firm desire and commitment to continue their relationships and not to change the status quo. For many, caring was also seen as a relational activity; set against the context of a past history of shared and meaningful experiences and understood with reference to past events. It was the natural extension of the love and support received in marriage. In this way, posing the question of 'why do you care?' to some of the men seemed somewhat preposterous.

Table 3 reports data on the other research questions explored. 
Table 3: Motivation to care, tasks performed, support services received and respondents' satisfaction with the principal care role $(n=26)$

\begin{tabular}{|c|c|}
\hline Reasons for caring & Percentages \\
\hline Love & $35 \%$ \\
\hline Marriage & $27 \%$ \\
\hline Love, marriage and duty (combination) & $20 \%$ \\
\hline Duty & $7 \%$ \\
\hline Other & $11 \%$ \\
\hline \multicolumn{2}{|l|}{ Caring tasks performed } \\
\hline \multicolumn{2}{|l|}{ Household services } \\
\hline Housework & $96 \%$ \\
\hline Meal preparation & $96 \%$ \\
\hline Finances & $100 \%$ \\
\hline Driving & $77 \%$ \\
\hline \multicolumn{2}{|l|}{ Non-personal care services } \\
\hline Medication & $88 \%$ \\
\hline Supervision & $81 \%$ \\
\hline \multicolumn{2}{|l|}{ Personal care services } \\
\hline Showering/bathing & $58 \%$ \\
\hline Dressing & $50 \%$ \\
\hline Grooming & $46 \%$ \\
\hline Feeding & $27 \%$ \\
\hline Walking & $23 \%$ \\
\hline \multicolumn{2}{|l|}{ Bodily function services } \\
\hline Urinary incontinence & $50 \%$ \\
\hline Faecal incontinence & $31 \%$ \\
\hline Toileting & $42 \%$ \\
\hline \multicolumn{2}{|l|}{ Formal support services received } \\
\hline Day respite & $31 \%$ \\
\hline Home help & $27 \%$ \\
\hline Domiciliary nurses & $23 \%$ \\
\hline \multicolumn{2}{|l|}{ Residential respite } \\
\hline Meals on wheels & $11 \%$ \\
\hline \multicolumn{2}{|l|}{ Informal support services received } \\
\hline Adult daughter & $58 \%$ \\
\hline Adult son & $11 \%$ \\
\hline \multicolumn{2}{|l|}{ Satisfaction with the care role } \\
\hline Seeing her happy smiling and comfortable & $27 \%$ \\
\hline Seeing her remain healthy & $23 \%$ \\
\hline Being together and having her still with me & $23 \%$ \\
\hline Seeing the meals well prepared & $8 \%$ \\
\hline Knowing l've done my best for her & $4 \%$ \\
\hline Nothing is satisfying & $4 \%$ \\
\hline Don't know & $11 \%$ \\
\hline
\end{tabular}




\section{Caring tasks performed}

Fourteen tasks associated with caregiving (Cahill, 1997) were read out to participants who were asked to identify which tasks they undertook routinely. For the majority, dementia care was a 24 hour around the clock responsibility. Two thirds $(n=16)$ reported they devoted 7 days weekly to the role, seven claimed they spent 4-6 days weekly caring and only one man (who also worked full time) reported he spent less than 4 days weekly caring (not shown). The table shows that a large proportion of male caregivers were actively involved in the multiple daily tasks of caregiving. More than $90 \%$ had responsibility for managing household finances, housework and meal preparation, and more than $80 \%$ took charge of medicating and supervising their wives. Between one quarter to one half, had responsibility for delivering hands-on personal care, including dressing, grooming, feeding and showering (see table 3). Analysis showed that more than half the sample $(n=14)$ undertook at least nine of these fourteen care tasks daily.

While most husbands were accustomed to managing domestic finances for all their lives, assuming responsibilities for meal preparation and housework were new activities, unfamiliar to many. For the majority, it seems the care role was modelled on earlier work roles, described in occupational language and executed in a systematic manner with care tasks following a linear progression. Several commented about the enjoyment they got from doing new domestic chores, keeping the house tidy and preparing nice meals. In one home, the carer described in much detail the type of roast meat and vegetables he was preparing that morning and then rather proud of his home produce, he invited the researcher to stay for lunch. Another 83 year old man surprised at his own culinary accomplishments re-echoed the words of several of the male caregivers when he commented: 'I now cook all the meals, I even make biscuits and cakes and I make everything we eat'.

\section{Incontinence management}

Since the issue of cross -gender caregiving, particularly men's limited involvement in delivering intimate personal care services to women has been highlighted in the literature (Ungerson, 1983), a particular interest was in exploring carers' attitudes to managing their wives bodily functions. A total of thirteen men $(50 \%)$ claimed they had responsibility for incontinence management, including the cleaning of faeces and urine and the changing of incontinence pads (see table 3). Eight male caregivers had wives who were doubly incontinent. Some of these women also exhibited other dementiarelated problem behaviours such as aggression, wandering and scatalia (the 
smearing of faeces). In general, caregivers did not find these hands-on tasks difficult to perform. When asked how they coped, the majority $(71 \%)$ reported they considered this as a routine aspect of care, and approached it pragmatically as a job which had to be done. There were only a few cases where respondents had difficulties managing their wives' bodily functions. The men's greater instrumentality, their matter of fact approach to caregiving and their ability to see moral dilemmas in terms of rights was reflected in many of the comments made about incontinence management:

It's part of what has to be done, you just get on with it.

It's no problem, it's something I have to do.

I've washed nappies, it's okay, it's part of the caring.

No worries.

\section{Formal support service and caregiving}

Caregivers were questioned about the use of government sponsored formal services. Data show (see table 3) that in general male caregivers received limited formal support with the physical and personal care services associated with caregiving. Three community care services, namely (i) day respite, (ii) home help, and (iii) domiciliary nurses were used by between approximately one quarter to one third of the sample. Interestingly, meals on wheels, a service which might have had the potential to make a key contribution to systems of support for male caregivers, was used by as few as three elderly men. The average number of services used was 1 . Thirteen (50\%) used either one or two services. A 87 year old man, the oldest carer in the sample, accessed the maximum number of services (four). Despite what might appear to be a low level of service support, most reported they were satisfied with the extent of government assistance provided. A small subgroup $(n=7)$ claimed they would have valued additional hours of domiciliary services or more respite care $(n=4)$.

\section{Informal support services and caregiving}

The role adult children played in providing secondary support to caregivers was explored. Interviews revealed that all but one of the men had adult children and in nineteen cases ( $73 \%$ ), children were reported to assist with caregiving. Closer investigation of data showed that help given was largely gendered with daughters $(n=15)$ rather than sons $(n=3)$ providing most assistance. Interventions were also of a practical nature and included help 
with household chores, transport, shopping and in-home respite. In line with literature findings (Parker, 1993), most carers seemed conscious of the constraints on their children's time (Twigg \& Atkin, 1994). Some were defensive about their children's involvement in parent care and expressions such as 'they have their own lives to live', 'they help as much as is possible', or 'they visit when they can' were not uncommon. Analyses also showed how adult children were rarely involved in the intimate tasks of personal care. The assistance offered by them tended to be intermittent rather than frequent. There were only four cases where daughters offered help more than once weekly. In one of these cases it seems that the extensive support offered by a daughter who herself also worked full time, was a critical factor enabling the male caregiver continue to work while providing home care:

My daughter helps, she gives me quite a lot because she's a barmaid and she works odd hours and I usually drop Mary (wife) at Annie's (daughter) place because I work in the bitumen game and sometimes I start really early. I drop her at Annie's place about 4 days a week see and the Alzheimer's and the Blue Nurses and so on pick her up from Annie's place.

\section{Satisfaction with the care role}

Respondents were asked 'what if anything do you find satisfying about providing home care?' All but three men could identify some positive aspects to the role (see Table 3$)$. Interestingly, for half $(n=13)$ a major source of satisfaction was seeing their loved one remaining healthy and looking happy. Caregivers seemed to attribute their spouses' health and well-being to the individually designed care they could provide at home. The point was clearly illustrated in several of the interviews:

I mean I'm trying to give her better than she'd have if she were to go to a home.

I'm keeping her alive, that's what we both agreed on.

I feel if I can share with her as much as I can she will have a longer run.

The salience of the marital relationship and carers' desire not to threaten that relationship by relinquishing home care was reflected in other responses. One quarter of the sample acknowledged that for them a source of satisfaction was the knowledge that they were responsible for either keeping their marriage and relationship together, 'its satisfying because I still have 
her with me, that's the name of the game' or from having their wives occasionally express gratitude to them. Interestingly for a few of the men, satisfaction was associated with a belief that nutritional meals were being prepared by them and caregiving was being well done. Again the language used by respondents tended to relate to the external working world of work and industry as the following testimonies show:

I can put together good quality food, I manufacture things by buying prepared foods and adding to them and making them taste nicer and serving them up a bit fancy. You take something out of a tin and you've got to do something with it to make it look nicer.

If you do a good job and your partner is content that's satisfying. Satisfaction was gained from doing the right thing, and in the context of warm loving relationships it was gratifying to provide care.

\section{Discussion}

This study is a first attempt in Queensland to broaden the debate on elderly male husband caregivers. Findings show the majority of respondents provided care to their wives diagnosed with Alzheimers' Disease and most women had a significant cognitive impairment. The majority of caregivers were partners in long-term marriages, had enjoyed happy and fulfilling relationships and were retired. When interviewed, most had been providing care for several years. Approximately one half managed their wives urinary incontinence, one third faecal incontinence and a large majority delivered personal and social services. Most carers received limited in-home formal support services. Respondents seemed to have few expectations about the level of assistance their adult children should give.

Results challenge literature findings which suggest that men adopt caring roles for reasons different to women. Findings demonstrate that for the majority, their motivation to care and their involvement in the role was similar to that demonstrated by women (Cahill, 1997; Ungerson, 1987; Lewis \& Meredith, 1988). Results show how feelings for family members were constructed within an historical context and the decision to care was embedded in pre-existing relationships and grounded in commitments arising from long-standing and fulfilling marriages. Caring was not always motivated by love or duty but rather, it was sometimes based on a whole range of inter-related factors including co-residence, reciprocity ('she would have done the same for me'), marriage obligations and concern. The men's 
injunction to care and their desire to do the right thing by not relinquishing home care was a recurrent theme emerging from the interviews. Results concur with Australian and overseas literature which suggests that age and marriage act as powerful forces determining caregiving roles and responsibilities (Bytheway, 1987; Cahill, 1999; Fisher, 1994).

Although the literature suggests that men set limits on their involvement in caregiving, and seek out and receive formal support services more readily than women (Johnson 1983; Enright, 1991) such was not a finding of this research where a different picture of the male caregiver emerged. Results from the study also contradict overseas literature which argues that men are more concerned with 'caring about' rather than having 'hands on' responsibilities (Kaye \& Applegate, 1990; Kramer \& Kipnis, 1995). Several men in the sample had responsibility for the intimate tasks of personal care including showering, bathing and managing their wives bodily functions. Within the sample, there also appeared to be no gender boundaries to delivering intimate care tasks. Although the research did not explore the social consequences of incontinence for male caregivers, it is likely that social isolation for these men may have increased over time according as their wives' incontinence could no longer be kept secret. Future research now needs to be undertaken to explore these issues in more depth.

Despite the high level of disability and cognitive impairment exhibited by care-receivers, an unexpected finding is the fact that gender appeared not to play a key role in determining public service receipt. In line with a similar study reported in the literature on female caregivers (Cahill \& Shapiro, 1998) few men in this research used meals on wheels, home help and home nursing. While reasons for low service use were not explored, there is evidence (see page 15) that some respondents would have welcomed additional support. The low use of community services may reflect the invisible nature of dementia care and the way in which older spouses may consider service interventions intrusive and may place boundaries around the private world of marriage thereby denying service providers access to their homes. Caution should be exercised in making inferences about gender differences in caregiving, through comparisons with studies of female caregivers. Male caregivers are more likely to be older than female caregivers and are more likely to be spouses rather than daughters. For this reason, male caregivers are likely to be more frail and have more disability and disease than female caregivers. These differences may confound any comparison of male and female caregivers. 


\section{Conclusions}

The research has important implications for policy makers and for practitioners working in the field of aged care. First, the finding that a time delay of up to two years arose before a medical diagnosis of dementia was made needs careful consideration. The finding suggests a need for more public education about the nature of dementing disorders to assist family carers seek earlier diagnoses. In particular, as new medications become available designed to help slow down memory deficits in some small groups of dementia, general practitioners need to be upskilled in relation to early diagnosis and management (Downs, 1999).

Secondly, the finding that some male caregivers would have valued additional information about dementia at diagnosis, has implications for how doctors communicate news of dementia. Results suggest the need for medical practitioners and others working in the area to better educate older male caregivers about dementia management from the early stage of the illness. Older carers may feel shocked at the time of initial diagnosis and much of the early information conveyed may be lost. There is a need to liaise more closely with these caregivers after initial diagnosis. There is a need to help older men adjust to the new care role often adopted late in life.

Thirdly, findings suggest a need to examine the way in which services to married couples are allocated (Twigg \& Atkin, 1995). particularly where a spouse caregiver is male. Several men in this research would have valued more formal support in caregiving. There are a large variety of reasons (economic, political, social, and psychological) why they may have failed to ask for or receive this support. One set of explanations may rest in society's norms and values and in assumptions held by men about the privacy of relationships and family life. Whether a caregiver uses services can be the product of his or her own expectations and values (Twigg \& Atkin, 1994). We know that most men felt obligated to comply with marriage obligations to care; some may not have wanted their spouses' disabilities exposed (Wenger, 1990). Other reasons may relate to the male view of the world; a desire by male caregivers to be seen to be coping, by not seeking out help. If barriers to the provision of social services to male caregivers have roots in gender issues, then strategies to provide services to these men need to be sensitive to the gendered context in which family caregiving takes place. The results suggest that although similarities exist between male and female caregivers in terms of motivation to care, care tasks performed and supports received, men manage the care role differently to women. Results suggest 
the need for professionals to be more cognisant of the psycho-social context of male caregiving.

Finally findings, showed that the labour of dementia care was substantial but there were also considerable personal and social rewards to be derived from the role for the men. While women may in later life resent the obligation to care since it disrupts their expected life trajectory, men it seems may well enjoy the new role. The challenge to policy makers and those working in the field is to develop ways by which rewards for men in caregiving roles can be further maximised. Findings suggest that community care policies need to be more sensitive to the gendered context of elderly care provision particularly when late life care roles are adopted by elderly frail men.

\section{Acknowledgments}

The research was funded by a grant from The Prince Charles Hospital Foundation. The author would like to thank the Foundation for its generous support of the work. Thanks are also extended to my colleagues and fellow members of the Prince Charles Hospital ACAT, who assisted with sample recruitment and data collection. The interview tapes were carefully transcribed by Coralie Millers to whom the author is indebted. A special word of thanks to Dr Kevin Balanda for reading and commenting on an earlier draft of the manuscript and to Dr Margaret Shapiro, director of postgraduate studies at the University of Queensland for guiding me at an early stage into this area. I would also like to thank Dr Chris Davis (Director of Geriatric Medicine) for his very positive support throughout this work.

\section{Notes}

1. A low score indicates a severe cognitive impairment.

2. The MBI is a ten item scale: a score of 0 to 20 suggests total dependence, 21-60, severe dependence, 61-90, moderate dependence and 91-99 slight dependence.

\section{References}

Aronson, J. (1992). Women's sense of responsibility for the care of old people: 'But who else is going to do it?' Gender \& Society, 6(1), 8-29. Australian Bureau of Statistics (ABS), 1993. Disability ageing and carers Australia. Summary of Findings. (Cat. No. 4430.0). Canberra: ABS. Borowski, A., Encel, S. \& Ozanne, E. (Eds.) (1997). Ageing and Social Policy in Australia. Melbourne: Cambridge University Press. 
Brody, E. (1990). Women in the Middle: Their Parent Care Years. New York: Springer Publishing Company.

Brown, P. (1996). Caregivers - the invisible workforce: Caregiver and gender issues. In Aged and Community Care Division and Office of Disability, Department of Human Services and Health (Eds.). Towards a National Agenda for Carers: Workshop Papers, 68-89.

Bytheway, W. (1987). Informal Care Systems: An Exploratory Study Within the Families of Older Steel Workers in South Wales, Report to Joseph Rowntree Memorial Trust, York.

Cahill, S. (1997). Choices and dilemmas in dementia care. Unpublished doctoral dissertation. University of Queensland, Brisbane.

Cahill, S. \& Shapiro, M. (1998). 'The only one you neglect is yourself.' Health outcomes for carers of spouses or parents with dementia. Do wives and daughter carers differ? Joumal of Family Studies, 4(1), 87-101.

Cahill, S. (1999). Caring in families: What motivates wives, daughters and daughter-in-laws to provide dementia care? Journal of Family Studies, 5(2), 235-247.

Downes, M. (1999). How to tell?: Disclosing a diagnosis of dementia. Generations, 23, 30-34.

Enright, R. (1991). Time spent caregiving and help received by spouses and adult children of brain impaired adults. The Gerontologist, 31(3), 375383.

Finch, J. \& Groves, D. (Eds.) (1983). A Labour of Love: Women Work and Caring. London: Routledge \& Kegan Paul.

Finch, J. \& Mason, J. (1993). Negotiating Family Responsibilities. London: Routledge.

Fisher, M. (1994). Man-made care: community care and older male carers. British Journal of Social Work, 24(6), 659-680.

Fitting, M., Rabins, P., Lucas, M, \& Eastham, J. (1986). Caregivers for dementia patients: A comparison of husbands and wives. The Gerontologist, 26(3), 248-252.

Gregory, D.M., Peters, N, \& Cameron, C. (1990). Male spouses as caregivers: towards an understanding of their experience. Journal of Gerontological Nursing, 16(3), 20-24.

Guberman, N. (1988). The family, women and caring: who cares for the carers? Resources of Feminist Research, 17(2), 37-40.

Harris, P. (1993). The misunderstood caregiver? A qualitative study of the male caregiver of Alzheimer's Disease victims. The Gerontologist, 33(4), 551-556. 
Hooyman, N. (1990). Women as caregiver of the elderly: implications for social welfare policy and practice. In D.E. Biegal and A. Blum (Eds.), Aging and Caregiving: Theory, Research and Policy. Newbury Park: Sage.

Johnson, C.L. (1983). Dyadic family relations and social support. The Gerontologist, 23(4), 377-383.

Kaye. L.W. \& Applegate, J.S. (1990). Men as Caregivers to the Elderly: Understanding and Aiding Unrecognised Family Support. Lexington Books.

Kramer, B. \& Kipnis, S. (1995). Eldercare and work-role conflict - toward an understanding of gender differences in caregiver burden. The Gerontologist, 35(3), 340-348.

Leira, A. (1994). Concepts of caring: loving thinking and doing. Social Science Review, 185-201.

Lewis, J. \& Meredith, B. (1988). Daughters who Care: Daughters Caring for Mothers at Home. London: Routledge \& Kegan Paul.

Mathew, L., Mattocks, K., \& Slatt, L. (1990). Exploring the roles of men caring for demented relatives. Journal of Gerontological Nursing, 16(10), 20-25.

McCallum, J. \& Geiselhart, K. (1996). Australia's New Aged: Issues for Young and Old. Sydney: Allen \& Unwin.

Miles, M.B. \& Huberman, A. M. (1994). Qualitative Data Analysis: An Expanded Sourcebook. Newbury Park: Sage.

Miller, B. (1987). Gender and control among spouses of the cognitively impaired: a research note. The Gerontologist, 27(4), 447-453.

Miller, B. (1990). Gender differences in spouse management of the caregiver role. In E. K. Abel \& M.K. Nelson (Eds.), Circles of Care: Work Identity and Women's Lives. Albany: State University of New York Press, 92-104.

Motenko, A. (1989). The frustrations, gratifications and well-being of dementia caregivers. The Gerontologist, 29(2), 166-172.

Opie, A. (1992). There's Nobody There. Community Care of the Confused Older Person. Auckland, NZ: Oxford University Press.

Paul, L. (1999). Caring for aged parents: phenomenology and relationships. Journal of Family Studies, 5(2), 207-219.

Parker, G. (1993). With This Body: Caring and Disability in Marriage. Buckingham: Open University Press.

Schofield, H., Herrman, H., Bloch, S., Howe, A., \& Singh, B. (1997). Profile of Australian caregivers: roles and circumstances. Australian \& New Zealand Journal of Public Health, 21(1), 59-66. 
Siriopoulos, G., Brown, Y. \& Wright, K. (1999). Caregivers of wives diagnosed with Alzheimer's Disease: husbands' perspectives. American Journal of Alzheimer's Disease, 14(2), 79-87.

Snyder, B. \& Keefe, K. (1985). The unmet needs of family caregivers for frail and disabled adults. Social Work in Health Care. 19, 1-13.

Stoller, E. \& Cutler, S. (1992). The impact of gender on configurations of care among elderly couples. Research on Aging, 14, 313-330.

Twigg, J. \& Atkin, K. (1994). Carers Perceived: Policy and Practice in Informal Care. Milton Keynes: Open University Press.

Twigg, J. \& Atkin, K. (1995). Carers and services: factors mediating service provision. Journal of Social Policy, 24(1), 5-30.

Ungerson, C. (1983). Women and caring: Skills tasks and taboos. In E. Gamarnikow, D. Morgan, J. Purvis \& D. Taylorson (Eds.). The Public and the Private. London: Heinmann.

Ungerson, C. (1987). Policy is Personal: Sex, Gender and Informal Care. London: Tavistock.

Wenger, G.C. (1990). Elderly carers: the need for appropriate interventions. Ageing \& Society, 10, 197-219.

Zarit, S., Todd, P. \& Zarit, J. (1986). Subjective burden of husbands and wives as caregivers: a longitudinal study. The Gerontologist, 26, pp. 260266. 
Copyright of Australian Journal of Social Issues is the property of Australian Council of Social Service and its content may not be copied or emailed to multiple sites or posted to a listserv without the copyright holder's express written permission. However, users may print, download, or email articles for individual use. 